\title{
Muscle Nicotinic Acetylcholine Receptors May Mediate Trans-Synaptic Signaling at the Mouse Neuromuscular Junction
}

\author{
๑Xueyong Wang, ${ }^{1}$ J. Michael McIntosh, ${ }^{2,3}$ and $\oplus^{-M a r k ~ M . ~ R i c h ~}{ }^{1}$ \\ ${ }^{1}$ Department of Neuroscience, Cell Biology, and Physiology, Wright State University, Dayton, Ohio 45435, ${ }^{2}$ George E. Wahlen Veterans Affairs Medical \\ Center, Salt Lake City, UT 84108, and '3epartment of Psychiatry, University of Utah, Salt Lake City, UT 84112
}

Block of neurotransmitter receptors at the neuromuscular junction (NMJ) has been shown to trigger upregulation of the number of synaptic vesicles released (quantal content, QC), a response termed homeostatic synaptic plasticity. The mechanism underlying this plasticity is not known. Here, we used selective toxins to demonstrate that block of $\alpha 1$-containing nicotinic acetylcholine receptors (nAChRs) at the NMJ of male and female mice triggers the upregulation of QC. Reduction of current flow through nAChRs, induced by drugs with antagonist activity, demonstrated that reduction in synaptic current per se does not trigger upregulation of QC. These data led to the remarkable conclusion that disruption of synaptic transmission is not sensed to trigger upregulation of QC. During studies of the effect of partial block of nAChRs on QC, we observed a small but reproducible increase in the decay kinetics of miniature synaptic currents. The change in kinetics was correlated with the increase in QC and raises the possibility that a change in postsynaptic nAChR conformation may be associated with the presynaptic increase in QC. We propose that, in addition to functioning in synaptic transmission, ionotropic muscle nicotonic nAChRs may serve as signaling molecules that participate in synaptic plasticity. Because nAChRs have been implicated in a number of disease states, the finding that nAChRs may be involved in triggering synaptic plasticity could have wide-reaching implications.

Key words: endplate; homeostatic; neurotransmitter; plasticity; synaptic; transmission

Significance Statement

The signals that initiate synaptic plasticity of the nervous system are still incompletely understood. Using the mouse neuromuscular junction as a model synapse, we studied how block of neurotransmitter receptors is sensed to trigger synaptic plasticity. Our studies led to the surprising conclusion that neither changes in synaptic current nor spiking of the presynaptic or postsynaptic cell are sensed to initiate synaptic plasticity. Instead, postsynaptic nicotinic acetylcholine receptors (nAChRs), in addition to functioning in synaptic transmission, may serve as signaling molecules that trigger synaptic plasticity. Because nAChRs have been implicated in a number of disease states, the finding that they may mediate synaptic plasticity has broad implications.

\section{Introduction}

The signals that initiate synaptic plasticity of the nervous system are still incompletely understood. The neuromuscular junction $(\mathrm{NMJ})$ is a synaptic preparation ideally suited to studies of synaptic plasticity because there is only one neurotransmitter and

\footnotetext{
Received June 26, 2017; revised Jan. 2, 2018; accepted Jan. 8, 2018.

Author contributions:X.W., J.M.M., and M.M.R. designed research; X.W. performed research; J.M.M. contributed unpublished reagents/analytic tools; X.W. and M.M.R. analyzed data; X.W. and M.M.R. wrote the paper.

This work was supported by National Institutes of Health (Grant P01NS057228 to M.M.R. and Grants GM49677 and GM103801 to J.M.M.). We thank Drs. Peter Wenner and Doju Yoshikami for helpful comments.

The authors declare no competing financial interests.

Correspondence should be addressed to MarkM. Rich, Department of Neuroscience, Cell Biology, and Physiology, Wright State University, 3640 Colonel Glenn, 251 Biological Sciences, Dayton, OH 45435. E-mail: mark.rich@wright.edu. DOI:10.1523/JNEUROSCI.1789-17.2018

Copyright $\odot 2018$ the authors $\quad 0270-6474 / 18 / 381725-12 \$ 15.00 / 0$
}

neurotransmitter receptor type present. At the adult mouse NMJ, release of acetylcholine (ACh) from the presynaptic terminal binds and opens a single type of nicotinic acetylcholine receptor (nAChR) containing two identical $\alpha$ subunits and a $\beta$, a $\delta$, and an $\varepsilon$ subunit (Auerbach, 2015). The presence of a uniform population of $n A C h R s$ simplifies interpretation of experiments in which plasticity of the synapse is studied in response to partial block of receptors.

Block of synaptic transmission at the NMJ triggers rapid upregulation of presynaptic transmitter release that serves to counteract the block of transmission and is thus termed homeostatic synaptic plasticity (Rich and Wenner, 2007; Turrigiano, 2012; Davis and Müller, 2015). A number of different blockers of $n A C h R s$ have been found to trigger increases of the number of 
synaptic vesicles released (quantal content, QC) to homeostatically regulate synaptic current at the NMJ of multiple species including mouse and human (Katz and Miledi, 1978; Miledi et al., 1978; Molenaar et al., 1979, 1991; Cull-Candy et al., 1980; Wilson, 1982; Harborne et al., 1988; Plomp et al., 1992, 1994; Tian et al., 1994; Plomp et al., 1995; Wang et al., 2010, 2016). Homeostatic regulation of synaptic current also occurs at the glutamatergic Drosophila NMJ after block of glutamate receptors (Frank et al., 2006). These studies suggest homeostatic regulation of QC at the NMJ is an evolutionarily conserved phenomenon.

There are at least two distinct forms of homeostatic upregulation of QC at the mouse NMJ. The first is triggered by block of neurotransmitter receptors and the mechanism is an increase in the number of releasable vesicles (the binomial parameter $n$ ); the second is triggered by block of evoked release and the mechanism is an increase in the probability of release (the binomial parameter $p$ ) (Wang et al., 2010). These pathways can be triggered independently and are additive (Wang et al., 2010).

It is not clear how disruption of synaptic activity is sensed to trigger homeostatic plasticity. Possibilities include spiking of the postsynaptic cell and block of synaptic transmission. At the Drosophila NMJ, the increase in QC occurs in the absence of evoked activity (Frank et al., 2006), suggesting that neither loss of spiking of muscle fibers nor block of evoked release of neurotransmitter is the signal that triggers upregulation of QC. Similarly, it has been found that homeostatic regulation of quantal amplitude in neurons occurs independently of spiking activity (Garcia-Bereguiain et al., 2016). It is assumed that current flow or depolarization occurring during spontaneous release of neurotransmitter is what is sensed to trigger the homeostatic response.

We probed how partial block of nAChRs is sensed to trigger homeostatic synaptic plasticity at the mouse NMJ. Our data suggest that block of postsynaptic $\alpha 1$-containing nAChRs triggers presynaptic plasticity and led to the surprising conclusion that neither evoked nor spontaneous synaptic transmission is sensed. Our data raise the possibility that binding of toxin to nAChRs triggers trans-synaptic signaling and the presynaptic increase in QC.

\section{Materials and Methods}

Ethical approval. All procedures involving animals were approved by the Wright State institutional animal care and use committee.

Mice. To easily visualize NMJs, mice expressing the YFP transgene driven by the Thy-1 promoter were used [B6.Cg-Tg(Thy1-YFP)16Jrs/J; The Jackson Laboratory). Mice with $\alpha 7$ subunit of nicotinic nAChRs knock-out were also obtained from The Jackson Laboratory (Chrna7). Both male and female mice were used for all experiments. No differences were noted between male and female mice.

Electrophysiological recording. The experimental procedures used to measure QC in the mouse tibialis anterior muscle have been described previously (Wang et al., 2004, 2016). Briefly, 2- to 3-month-old mice were killed using $\mathrm{CO}_{2}$ inhalation and the tibialis anterior muscle was removed, pinned in a Sylgard plated dish and stained with $10 \mu \mathrm{M} 4-(4-$ diethylaminostyryl)- $\mathrm{N}$-methylpyridinium iodide (4-Di-2ASP; Invitrogen) to visualize NMJs using an upright epifluorescence microscope. Muscle strips were perfused at a speed of 3-6 ml per minute with external solution containing the following (in $\mathrm{mm}$ ): $118 \mathrm{NaCl}, 0.7 \mathrm{MgCl}_{2}, 2$ $\mathrm{CaSO}_{4}, 3.5 \mathrm{KCl}, 26.2 \mathrm{NaHCO}_{3}, 1.7 \mathrm{NaH}_{2} \mathrm{PO}_{4}$, and 5.5 glucose, equilibrated with $95 \% \mathrm{O}_{2}$ and $5 \% \mathrm{CO}_{2}$, pH 7.3-7.4, $20-22^{\circ} \mathrm{C}$. For experiments in which temperature was increased to $32^{\circ} \mathrm{C}$, an automatic temperature controller (Warner Instruments) was used.

Endplates were imaged and muscle fibers were impaled within $100 \mu \mathrm{m}$ of the NMJ to ensure good space clamp of the NMJ region. Endplate currents (EPCs) were recorded using two-electrode voltage clamp while the nerve branch to the tibialis anterior muscle was stimulated via a tungsten bipolar electrode (FHC).

Unless otherwise indicated, muscle fibers were crushed on both ends away from the NMJ band to eliminate contractions upon nerve stimulation and the holding potential was set at $-45 \mathrm{mV}$. In some experiments, a more negative potential was required to detect miniature EPCs (mEPCs) due to block of postsynaptic nAChRs. In these experiments, muscle fibers were not crushed and contraction was prevented by addition of $\mu$-conotoxin GIIIB ( $\mu$-Ctx; Alomone Labs) to the external solution (final toxin concentration was $1-3 \mu \mathrm{M}$ ) to inhibit muscle $\mathrm{Na}^{+}$ channels. We have shown that QC obtained from both preparations is identical (Wang et al., 2004, 2005).

The QC corresponding to a given EPC was calculated from the ratio of the amplitude the EPC to the average of amplitude of at least $20 \mathrm{mEPCs}$ obtained during the $20 \mathrm{~s}$ before and the $20 \mathrm{~s}$ after the EPC. For bars graphs of QC before and after block of nAChRs, EPC amplitude was determined from an average of $10 \mathrm{EPCs}$ evoked at $0.5 \mathrm{~Hz}$, whereas $\mathrm{mEPC}$ amplitude was determined from an average obtained from at least $30 \mathrm{mEPCs}$ recorded over a $1 \mathrm{~min}$ period.

Drugs. Drugs were applied either by adding into the bathing solution or by pressure puff delivery with a picospritzer II (20 psi) as described previously (Wang et al., 2016). $\alpha$-bungarotoxin (BTX), D-tubocurarine (D-TC), carbachol (CCh), vecuronium bromide, succinylcholine chloride, gallamine, mecamylamine hydrochloride, atropine, and acetylcholine chloride were all from Sigma-Aldrich. $\alpha$-conotoxin MI ( $\alpha$-CtxMI) and $\alpha$-conotoxin ArIB[V11L;V16D] ( $\alpha$-CtxArIB) were provided by Dr. McIntosh.

Experimental design and statistical analysis. Data were recorded from the same muscle (often the same NMJ) before and after drug treatment. Nested ANOVA (SYSTAT; Systat Software) was used for comparing the effect of drugs and other experimental manipulations. Details of the statistical tests used and the values obtained are listed in Table 1. Plots and curve fittings were made using Sigmaplot software (Systat Software). Averaged results are expressed as mean \pm SE. $p<0.05$ and $p<0.01$ are denoted by one and two asterisks, respectively.

\section{Results}

Block of nAChRs triggers upregulation of QC independently of evoked release, membrane potential, and synaptic current

We and others found previously that block of nAChRs at the mammalian NMJ at room temperature triggers an increase in QC (Katz and Miledi, 1978; Miledi et al., 1978; Molenaar et al., 1979, 1991; Cull-Candy et al., 1980; Wilson, 1982; Harborne et al., 1988; Plomp et al., 1992, 1994; Tian et al., 1994; Plomp et al., 1995; Wang et al., 2010, 2016). To confirm that the finding is physiologically relevant, we examined whether it occurred at the more physiologic temperature of $32^{\circ} \mathrm{C}$. Increasing temperature to $32^{\circ} \mathrm{C}$ increased mean mEPC amplitude from $1.44 \pm 0.14$ to $1.90 \pm 0.08 \mathrm{nA}(n=8 \mathrm{NMJs})$ and accelerated the rate of decay from $1.04 \pm 0.07$ to $0.59 \pm 0.04 \mathrm{~ms}$. There was no effect on QC $\left(56.6 \pm 2.6\right.$ to $\left.55.8 \pm 2.5, t_{(7)}=1.6, p=0.15\right)$. These results are similar to temperature-dependent changes reported previously at a central synapse (Kushmerick et al., 2006). The finding that QC does not change with increased temperature suggests that neither the number of releasable vesicles nor the probability of release has significant temperature dependence. When the temperature was $32^{\circ} \mathrm{C}$, the addition of $0.1 \mu \mathrm{M} \mathrm{D}$-TC triggered an increase in QC $\left(45.1 \%, n=9\right.$ NMJs, $\left.t_{(8)}=-4.765, p=0.001\right)$ that was similar to the increase occurring at room temperature. These data suggest that, at both room temperature and at physiologic temperature, partial block of nAChRs triggers an increase in QC.

There are several ways that the postsynaptic cell might sense reduction in synaptic activity. One is through reduction in postsynaptic spiking activity. This has been the mechanism proposed for detection of reduced network activity in neuronal systems 
Table 1. Data statistics

\begin{tabular}{|c|c|c|c|}
\hline Reference & Test & Result & Method \\
\hline \multirow[t]{2}{*}{ Temperature } & Raise to $32^{\circ} \mathrm{C}$ on $Q \mathrm{C}$ & $t_{(7)}=1.626, p=0.148$ & Paired $t$ test \\
\hline & $\mathrm{D}-\mathrm{TC}$ on $\mathrm{QC}$ at $32^{\circ} \mathrm{C}$ & $t_{(8)}=-4.765, p=0.00142$ & Paired $t$ test \\
\hline Fig. 1D & Holding at $-40 \mathrm{mV}$ and $-90 \mathrm{mV}$ on $Q \mathrm{C}$ & $t_{(9)}=-0.635, p=0.541$ & Paired $t$ test \\
\hline Fig. $2 \mathrm{~A}$ & Baseline QC (QC) & $F_{(3,15)}=0.805, p=0.499$ & ANOVA \\
\hline \multirow[t]{5}{*}{ Fig. $2 A$} & D-TC on QC & & Paired $t$ test \\
\hline & Control & $t_{(21)}=-11.467, p=1.67 \mathrm{E}-10$ & \\
\hline & $\alpha \mathrm{CtxArlB}$ & $t_{(8)}=-10.814, p=4.72 \mathrm{E}-6$ & \\
\hline & Atropine & $t_{(4)}=-8.102, p=0.00126$ & \\
\hline & $\alpha 7 \mathrm{~K} 0$ & $t_{(19)}=-7.316, p=6.15 \mathrm{E}-7$ & \\
\hline Fig. 2B & $\alpha$-Ctx MI on $Q \mathrm{C}$ & $F_{(2,6)}=9.787, p<0.0001$ & ANOVA \\
\hline Fig. $3 C$ & D-TC on QC with CCh puff & $t_{(9)}=-15.213, p=9.98 \mathrm{E}-8$ & ANOVA \\
\hline \multirow[t]{4}{*}{ Fig. $3 G$} & Effect of ACh & & ANOVA \\
\hline & EPC & $F_{(1,8)}=72.463, p<0.0001$ & \\
\hline & $\mathrm{mEPC}$ & $F_{(1,8)}^{(1,0)}=184.117, p<0.0001$ & \\
\hline & QC & $F_{(1,8)}=0.267, p=0.667$ & \\
\hline \multirow[t]{4}{*}{ Fig. $3 \mathrm{H}$} & Ctrl vs $+\mathrm{ACh}+$ atropine & & ANOVA \\
\hline & EPC & $F_{(16)}=25.143 p<0.0001$ & \\
\hline & mEPC & $F_{(1,6)}=31.179, p \leq 0.0001$ & \\
\hline & QC & $F_{(1,6)}=0.026, p=0.873$ & \\
\hline \multirow[t]{4}{*}{ Fig. 3H } & Ctrl vs ACh + atropine + D-TC & & ANOVA \\
\hline & EPC & $F_{(1.6)}=70.508, p \leq 0.0001$ & \\
\hline & $\mathrm{mEPC}$ & $F_{(1,6)}^{(1,6)}=269.432, p \leq 0.0001$ & \\
\hline & $Q C$ & $F_{(1,6)}^{(1,0)}=25.644, p \leq 0.0001$ & \\
\hline \multirow[t]{4}{*}{ Fig. $3 \mathrm{H}$} & $\mathrm{ACh}+$ atropine vs ACh + atropine + D-TC & & ANOVA \\
\hline & EPC & $F_{(1,6)}=10.924, p=0.001$ & \\
\hline & $\mathrm{mEPC}$ & $F_{(1,6)}^{(1,0)}=250.029, p \leq 0.0001$ & \\
\hline & $Q C$ & $F_{(1,6)}=25.644, p \leq 0.0001$ & \\
\hline \multirow[t]{4}{*}{ Fig. $4 \mathrm{~A}$} & Before vs vecuronium & & ANOVA \\
\hline & EPC & $F_{(1,10)}=126.367, p<0.0001$ & \\
\hline & $\mathrm{mEPC}$ & $F_{(1,10)}=805.135, p<0.0001$ & \\
\hline & QC & $F_{(1,10)}=42.313, p<0.0001$ & \\
\hline \multirow[t]{4}{*}{ Fig. 4A } & Vecuronium vs washout & & ANOVA \\
\hline & EPC & $F_{(1,10)}=54.36, p<0.0001$ & \\
\hline & $\mathrm{mEPC}$ & $F_{(1,10)}=596.527, p<0.0001$ & \\
\hline & QC & $F_{(1,10)}=27.124, p<0.0001$ & \\
\hline \multirow[t]{4}{*}{ Fig. 4B } & Before vs mecamylamine & & ANOVA \\
\hline & EPC & $F_{(1,4)}=7.92, p=0.006$ & \\
\hline & $\mathrm{mEPC}$ & $F_{(1,4)}=338.71, p<0.0001$ & \\
\hline & $Q C$ & $F_{(1,4)}=54.659, p<0.0001$ & \\
\hline \multirow[t]{4}{*}{ Fig. $4 \mathrm{~B}$} & Mecamylamine vs washout & & ANOVA \\
\hline & EPC & $F_{(1,4)}=10.835, p=0.002$ & \\
\hline & $\mathrm{mEPC}$ & $F_{(1,4)}^{(1,4)}=602.623, p<0.0001$ & \\
\hline & QC & $F_{(1,4)}^{(1,4)}=39.211, p<0.0001$ & \\
\hline \multirow[t]{4}{*}{ Fig. 4D } & Before vs succinylcholine & & ANOVA \\
\hline & EPC & $F_{(1,8)}=273.314, p<0.0001$ & \\
\hline & $\mathrm{mEPC}$ & $F_{(1,8)}=493.958, p<0.0001$ & \\
\hline & $Q C$ & $F_{(1,8)}=0.528, p=0.498$ & \\
\hline \multirow[t]{4}{*}{ Fig. 4D } & Succinylcholine vs washout & & ANOVA \\
\hline & EPC & $F_{(1,8)}=110.816, p<0.0001$ & \\
\hline & mEPC & $F_{(1,8)}=172.376, p<0.0001$ & \\
\hline & QC & $F_{(1,8)}=0.486, p<0.487$ & \\
\hline \multirow[t]{9}{*}{ Fig. 5B } & $\mathrm{mEPC}$ decay tau change by & & Paired $t$ test \\
\hline & BTX & $t_{(18)}=6.458, p=4.48 \mathrm{E}-6$ & \\
\hline & D-TC & $t t_{17)}=12.355, p=1.35 \mathrm{E}-9$ & \\
\hline & Gallamine (GT) & $t_{(9)}=5.825, p=2.52 \mathrm{E}-4$ & \\
\hline & Mecamylamine & $t_{(4)}=7.263, p=0.00191$ & \\
\hline & Vecuronium & $t_{(12)}=5.048, p=2.85 \mathrm{E}-4$ & \\
\hline & Succinylcholine & $t_{(11)}=-1.956, p=0.0790$ & \\
\hline & $\mathrm{ACh} / \mathrm{CCh}$ & $t_{(21)}=3.705, p=0.0014$ & \\
\hline & BTX vs ACh/CCh on decay tau & $t_{(38)}=4.197, p=1.57 \mathrm{E}-4$ & $t$ test \\
\hline
\end{tabular}

(Turrigiano, 2012). In our system, this was not a possibility because postsynaptic spiking was prevented by crushing muscle fibers to depolarize the membrane potential and inactivate sodium channels. Despite the loss of postsynaptic spiking, partial block of nAChRs by D-TC triggered rapid upregulation of QC (Fig. 1A,B).

A second possibility is that depolarization of the postsynaptic muscle fiber during evoked release is sensed to trigger the homeo- 
A

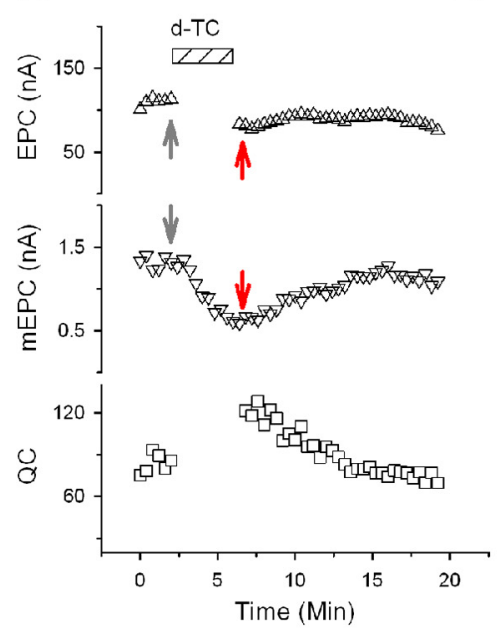

C

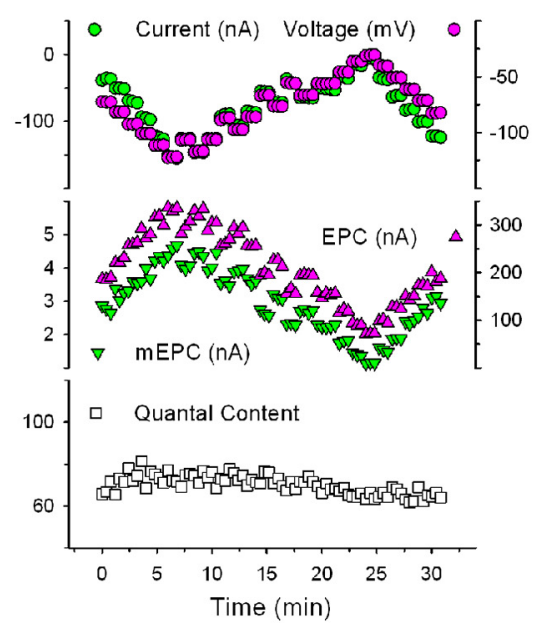

A
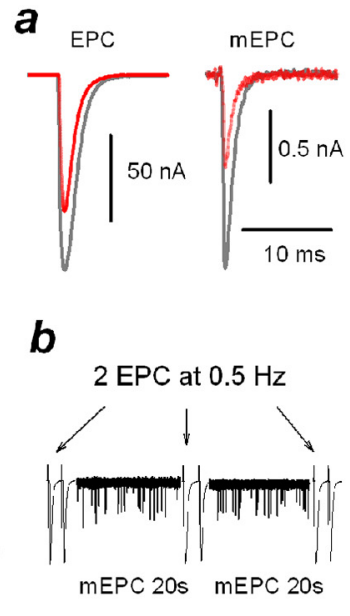

D

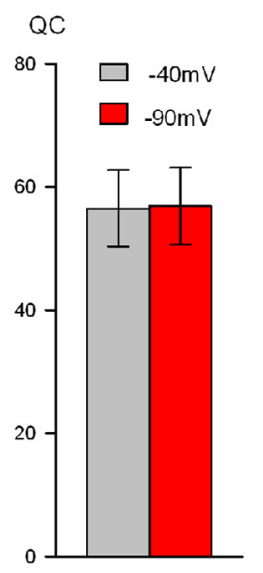

Figure 1. Rapidly reversible increase in $Q C$ is triggered independent of synaptic current and evoked release. $\boldsymbol{A}$, Increase in QC triggered by blocking $n A C h R s$ is not dependent on evoked $A C h$ release. EPC (top) and $\mathrm{mEPC}$ (middle) were recorded alternately by repeating the protocol shown in the bottom row of $\boldsymbol{B}$. The corresponding QC was calculated from the ratio of the EPC amplitude/average $\mathrm{mEPC}$ (see Materials and Methods) and plotted in the bottom trace. The bathing solution contained $0.1 \mu \mathrm{M} \mathrm{D-TC}$ as indicated by striped bar. Nerve stimulation/EPC collection was paused during D-TC infusion. $B \boldsymbol{a}$, Representative traces of EPC and $\mathrm{mEPC}$, from the experiment shown in $A$ before (gray) and during (red) infusion of D-TC at the times indicated by the correspondingly colored arrows in $\boldsymbol{A}$. $\boldsymbol{B} \boldsymbol{b}$, Recording protocol used for experiments in which $Q C$ was followed in individual fibers during infusion of $n A C h R$ blockers. Two $E P C s$ at $0.5 \mathrm{~Hz}$ and $20 s$ of $m E P C s$ were alternately recorded and the averaged values were used to calculate corresponding QC and construct the plot (e.g., $\boldsymbol{A}$ and $\boldsymbol{C}$ ). EPC and mEPC amplitudes are scaled differently so that both fit on the same plot. $C, Q C$ is not affected by varying EPC and mEPC amplitude by changing the muscle fiber holding potential. Using 2-electrode voltage clamp, the muscle voltage in the region of the endplate was varied by $5 \mathrm{mV}$ every minute (top, green circle). Muscle action potentials were prevented by the presence of $2 \mu \mathrm{M} \mu$-conotoxin in the bathing solution. The holding current (top, purple circle) is also plotted. EPCs and mEPCs (middle) were acquired alternately by repeating the protocol shown in $\boldsymbol{B} \boldsymbol{b}$. The calculated $Q \boldsymbol{C}$ is shown at the bottom and was unvarying despite a $>2$-fold change in EPC and $\mathrm{mEPC}$ amplitude. D, EPC and $\mathrm{mEPC}$ were collected at holding potentials of both $-40 \mathrm{mV}$ and $-90 \mathrm{mV}$ on $10 \mathrm{NMJs}$ and $\mathrm{QC}$ was compared. Holding potential exerted no significant effect on $Q C\left(t_{(9)}=-0.635, p=0.541\right)$.

static upregulation of QC. We tested this possibility in two ways. First, we voltage clamped individual muscle fibers such that the membrane potential in the region of the NMJ was constant before, during, and after the infusion of D-TC. Despite a constant membrane potential, QC was still upregulated by infusion of D-TC (Fig. 1A). Second, we measured QC in individual NMJs

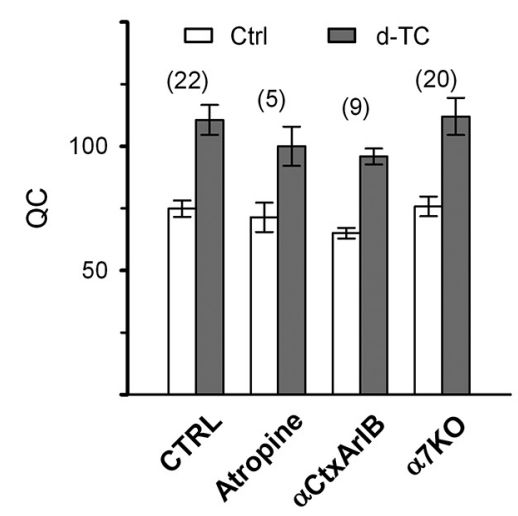

B

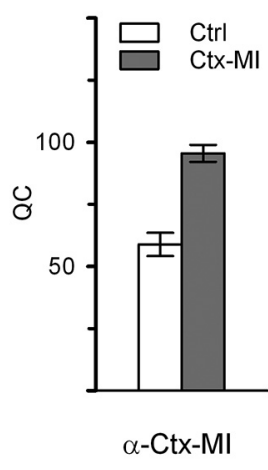

Figure 2. Increase in $\mathrm{QC}$ is triggered by block of $\mathrm{nAChRs}$ containing $\alpha 1$ subunits. $A, \mathrm{QC}$ was measured before and in the presence of D-TC $(0.1 \mu \mathrm{m})$ in control muscle ( $n=8$ mice, $22 \mathrm{NMJs})$, in muscle pretreated with atropine $(10 \mu \mathrm{M})$ to block muscarinic AChRs (2 mice, $5 \mathrm{NMJs})$, in muscle pretreated with $\alpha$-CtxArlB (17 nm) to block $\alpha 7$ containing nAChRs ( 3 mice, 9 NMJs), and in muscle from mice lacking nAChRs composed of $\alpha 7$ subunits ( 6 mice, 20 NMJs). There was no significant difference in baseline QC among the 4 groups $\left(F_{(3,15)}=0.805, p=0.499\right.$, ANOVA) and D-TC triggered a significant increase in QC in all 4 groups (Table 1). $B, Q C$ is significantly increased by $\alpha$-Ctx MI ( $40 \mathrm{~nm}$ ), which blocks nAChRs containing the $\alpha 1$ subunit. Control, $n=3$ mice, $30 \mathrm{NMJs}$; in the presence of $\alpha$-Ctx MI, $n=3$ mice, 50 NMJs. ANOVA, $F_{(2,6)}=9.787, p=$ 0.0001 .

and then infused D-TC in the absence of presynaptic spikes triggered by nerve stimulation. The increase in QC was evident in the EPC evoked by the very first nerve stimulation after infusion of D-TC (Fig. $1 A . n=6$ NMJs), but not when D-TC was omitted ( $n=4$ NMJs). These data indicate that the increase in QC can occur in the absence of changes in muscle membrane potential and in the absence of prior evoked release.

The upregulation of QC could be triggered by interruption of $\mathrm{nAChRs}$ activation during spontaneous release of ACh. Spontaneous release of vesicles containing ACh occurs at the NMJ at a rate of $\sim 1 \mathrm{~Hz}$ and triggers mEPCs. One way that mEPCs might signal is through depolarization of the membrane potential; however, this was ruled out by the voltage-clamp experiments described above. The next possibility that we considered is that reduction in $\mathrm{mEPC}$ current (rather than depolarization) is sensed to trigger the upregulation of QC. We altered the holding potential of the postsynaptic muscle fiber to alter driving force for current flow through nAChRs (Fig. 1C,D). Increasing and decreasing $\mathrm{mEPC}$ amplitude by twofold by altering holding potential had no effect on QC (Fig. 1C,D). These data suggest that reduction in postsynaptic current is not the trigger of increases in QC.

\section{Block of nicotinic $\alpha 1$ containing nAChRs triggers the increase in QC}

The finding that reduction in postsynaptic current does not trigger upregulation of presynaptic QC caused us to consider that the nAChRs triggering the upregulation of QC might be on either the presynaptic terminal or the Schwann cell. Evidence for the presence of AChRs on terminal Schwann cells at the mouse NMJ comes from a study showing that Schwann cell $\mathrm{Ca}^{2+}$ transients are triggered by nerve stimulation or application of ACh (Rochon et al., 2001). Muscarinic AChRs appear to be involved as the Schwann cell $\mathrm{Ca}^{2+}$ transients were blocked by atropine and were unaffected by application of BTX (Rochon et al., 2001). We applied atropine to muscles and found this triggered no change in QC (Fig. 2A). Application of D-TC after application of atropine 
A

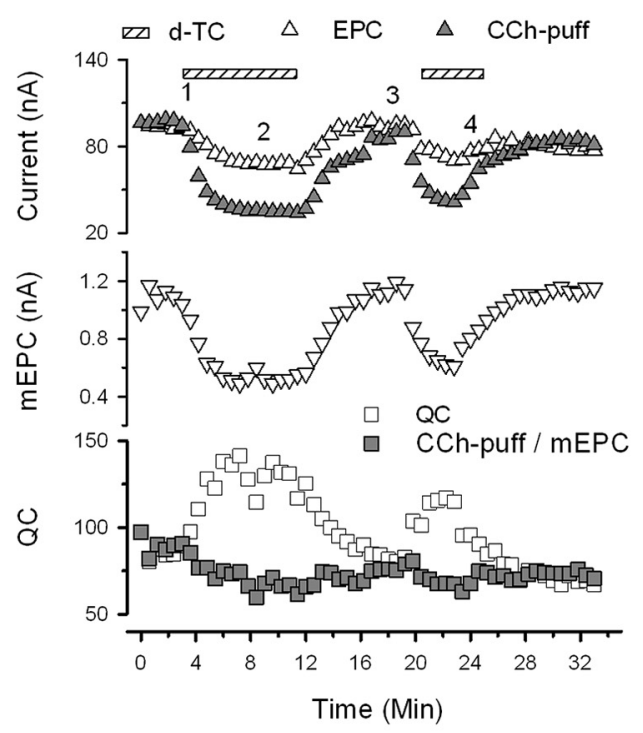

D
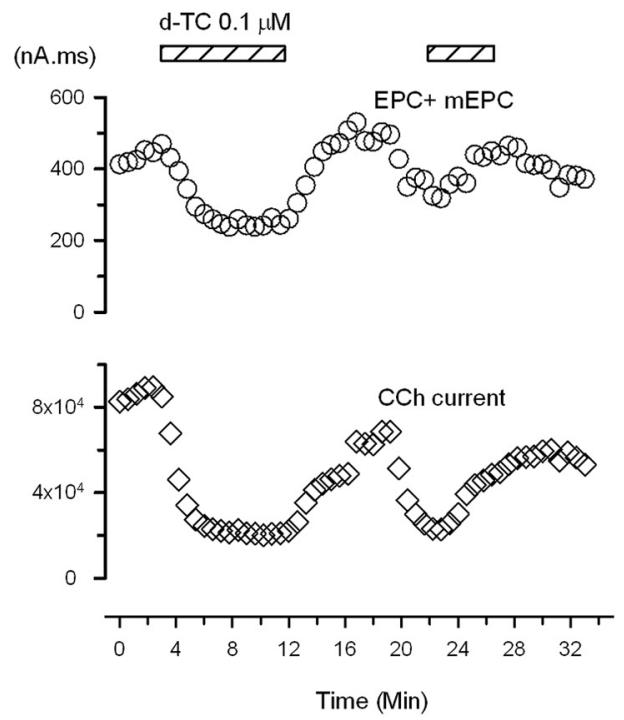

G
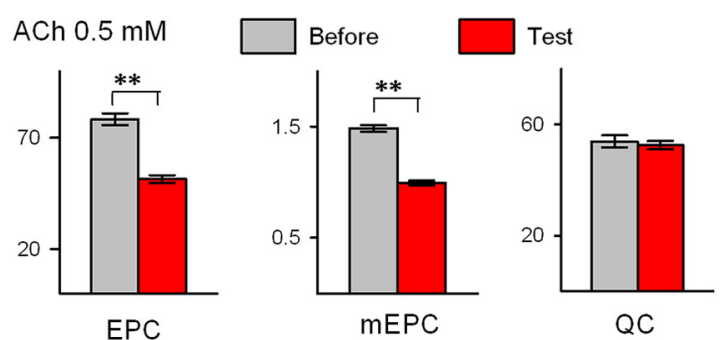

B

MEPC
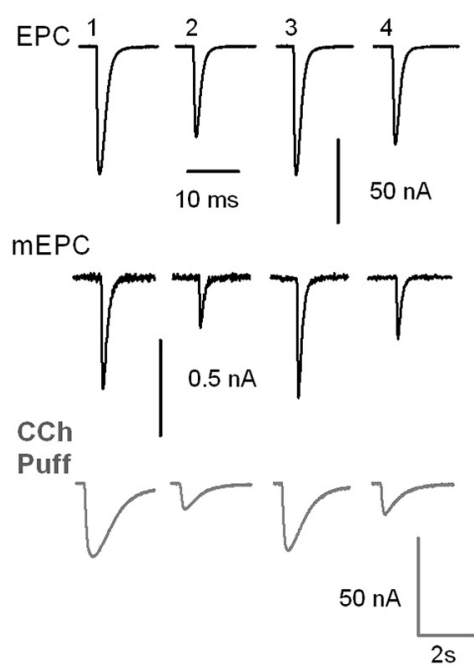

E

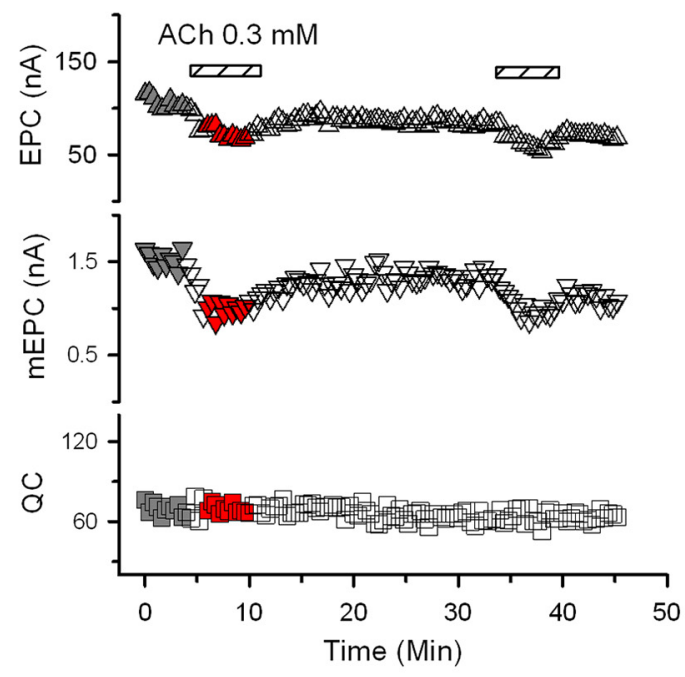

EPC

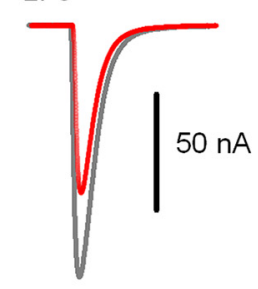

$10 \mathrm{~ms}$

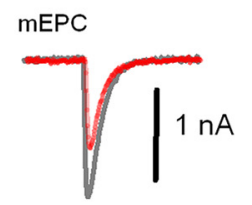

Figure 3. Upregulation of $\mathrm{QC}$ is independent of synaptic function. $A$, Pulsatile application of the agonist CCh that produces large CCh-gated currents does not prevent the D-TC-induced increase in QC. EPC, puffed CCh-evoked current, and mEPC were acquired alternately by the protocol shown in Cb. Average EPC (up triangle, open, average mEPC (down triangle), and QC (square, open) were plotted against time. For comparison, the value of CCh-evoked current (up triangle, filled) was normalized to that of EPC recorded before D-TC infusion, and the ratio of CCh-evoked current/mEPC were also plotted (square, filled) along-side QC. The bathing solution was switched to a solution containing $0.1 \mu \mathrm{m} \mathrm{D-TC}$ as indicated by horizontal bars. $\boldsymbol{B}$, Representative traces of EPC, CCh-evoked current, and $\mathrm{mEPC}$ were taken at times denoted by the numbers in $A$. Ca, Comparison of QC increases (percentage of control) by D-TC infusion with ( $n=22$, same data as in Fig. $2 A$ control) / without $(n=11)$ puffing of $\mathrm{CCh}\left(t_{(9)}=-15.213, p=9.98 \mathrm{E}-8\right.$, paired $\left.t\right)$. $(\boldsymbol{b}$, Protocol used in $\boldsymbol{A}$. It is a variation of protocol shown in Figure $1 B b$. with addition of pressure puffing of agonist onto the NMJ being recorded after acquisition of EPC and recording of $25 \mathrm{~s} \mathrm{mEPC} \mathrm{in} \mathrm{each} \mathrm{cycle.} \boldsymbol{D}$, Total postsynaptic current for a given time period of the recording shown in $A$ was measured by taking the integral of the various currents over each $25 \mathrm{~s} \mathrm{epoch}$. The top panel is a plot of the summed integrals of EPCs and mEPCs before and after D-TC infusion. The bottom panel is a plot of the current in response to intermittent application of carbachol. Despite the CCh induced currents being 200 times larger than the combined total EPC and mEPC currents in the same recording cycle, the D-TC-induced increase in QC is robust. $E$, Desensitization of $n A C h R s$ does not trigger an increase in $Q C$. Plots of average EPC, $\mathrm{mEPC}$, and QC obtained using the protocol shown in Figure $1 B b$. Despite a $40 \%$ reduction in EPC and mEPC amplitudes (measured at the time indicated by the red symbols), there was no increase in QC. $\boldsymbol{F}$, Averaged EPC and mEPC traces before (gray) and (Figure legend continues.) 
triggered the normal increase in QC (Fig. 2A). These data indicate that muscarinic AChRs are not involved in D-TC-induced increase in QC at the NMJ.

Due to the rapidity of the upregulation of QC after D-TC, it has been hypothesized that block of presynaptic nAChRs triggers the upregulation (Bowman et al., 1990; MacDermott et al., 1999). $\mathrm{D}$-TC-sensitive $\alpha 7$-subunit-containing nAChRs are found on many presynaptic terminals in the CNS (Albuquerque et al., 2009) such that block of this type of nAChR could be involved in the D-TC-induced increase in QC. $\alpha$-CtxArIB is a rapid-acting blocker of $\alpha 7$ containing nAChRs (Whiteaker et al., 2007; Innocent et al., 2008) and $\alpha$-CtxArIB triggered no increase in QC (Fig. $2 A$ ). Furthermore, the increase in QC triggered by application of D-TC was unaffected by prior block of $\alpha 7 \mathrm{nAChRs}$ with $\alpha$-CtxArIB. We also applied D-TC to NMJs from mice lacking the $\alpha 7 \mathrm{AChR}$ subunit ( $\alpha 7 \mathrm{KO}$ mice) and found an increase in QC that was similar to the increase present in wild-type siblings (Fig. 2A). These data suggest block of presynaptic $\alpha 7$ containing nAChRs is not the trigger for the increase in QC.

$\alpha 1$-containing $\mathrm{nAChRs}$ are present in high concentration on the postsynaptic muscle fiber at the NMJ and, to our knowledge, have not been shown to be expressed by either motor neurons or Schwann cells. $\alpha$-CtxMI is a selective blocker of $\alpha 1$-containing nAChRs (Johnson et al., 1995; Luo and McIntosh, 2004) and it triggered an increase in QC similar to that seen with D-TC (Fig. $2 B$ ). These data strongly suggest that block of $\alpha 1$-containing $\mathrm{nAChRs}$ on muscle is the trigger for upregulation of QC.

\section{Upregulation of QC is independent of synaptic transmission}

Synaptic current through nAChRs is primarily carried by $\mathrm{Na}^{+}$ and $\mathrm{K}^{+}$ions, but there is significant $\mathrm{Ca}^{2+}$ current as well (Bregestovski et al., 1979; Adams et al., 1980; Vernino et al., 1994). At the mouse, frog, and Drosophila NMJ, it has been proposed that $\mathrm{Ca}^{2+}$ flow through postsynaptic receptors is sensed to trigger homeostatic plasticity (Frank et al., 2006; Ouanounou et al., 2016). Changes in $\mathrm{Ca}^{2+}$ entry through nAChRs will be relatively insensitive to changes in holding potential becauase the driving force for $\mathrm{Ca}^{2+}$ entry is large. Therefore, the lack of effect of changing holding potential does not rule out a role for $\mathrm{Ca}^{2+}$ current through nAChRs.

To examine the possibility that reduced $\mathrm{Ca}^{2+}$ entry through nAChRs is sensed, we increased synaptic current by directly applying agonist during infusion of D-TC. Carbachol (CCh) was selected as the agonist as it causes less desensitization than ACh. The duration and amplitude of the CCh-gated current in response to intermittent application of CCh was far greater than the amplitude of currents carried by mEPCs and EPCs, yet pulsatile application of CCh did not prevent the upregulation of QC triggered by D-TC (Fig. $3 A-C, n=11$ NMJs from 6 mice). These data demonstrate that $\mathrm{D}-\mathrm{TC}$ can still trigger an increase in QC, even when $\mathrm{Ca}^{2+}$ entry is greatly increased relative to baseline by puffs of CCh. A caveat is that the large increases in $\mathrm{Ca}^{2+}$ entry through

\section{$\leftarrow$}

(Figure legend continued.) in the presence of $A C h$ (red) taken from times corresponding to colored symbols on the plots shown in D. G, Mean data from 10 muscles treated with ACh: $n=$ 43 NMJs before and 102 NMJs during ACh infusion (Table 1). $\boldsymbol{H}$, Mean data from 8 muscles before (white, $n=38$ NMJs) treated with ACh $0.1 \mathrm{~mm}$ and atropine $10 \mu \mathrm{m}$ (gray, $n=43$ NMJs) and with addition of $0.1 \mu \mathrm{m}$ D-TC ( $r e d, n=56 \mathrm{NMJs}$ ). Nested analysis showed significant reductions in EPC and $m E P C$ amplitude after application of $A C h$ and further significant reductions after addition of D-TC. ${ }^{* *} p<.01$. QC was statistically increased after D-TC infusion, whereas application of $\mathrm{ACh}$ and atropine alone had no effect (Table 1).
nAChRs triggered by CCh do not mimic the small pulsatile $\mathrm{Ca}^{2+}$ entry occurring during mEPCs.

We wished to determine whether we could reduce $\mathrm{Ca}^{2+}$ entry during $\mathrm{mEPCs}$ without triggering an increase in QC. We reduced the amplitude of mEPCs by application of ACh to trigger desensitization. To further confirm that upregulation of QC is independent of the reduction in synaptic current $/ \mathrm{Ca}^{2+}$ entry, we reduced the amplitudes of synaptic currents by application of $\mathrm{ACh}$ to trigger desensitization. We applied ACh to the bath at a dose $(0.3-0.5 \mathrm{~mm})$ that reduced mEPC amplitude by $>30 \%$. This degree of reduction in mEPC amplitude normally reliably triggers an increase in QC after application of D-TC. However, when mEPC amplitude was reduced by desensitization of nAChRs, there was no increase in QC (Fig. $3 D-F$ ). Similar results were obtained with 10 to $30 \mu \mathrm{M}$ CCh ( $n=10$ NMJs, data not shown). These results are consistent with the possibility that reduction in $\mathrm{Ca}^{2+}$ entry/current during mEPCs is not what is sensed to trigger the upregulation of QC.

We next considered whether an aspect of synaptic function that we did not measure might be involved in signaling the increase in QC. Several studies have suggested there is nonvesicular release of ACh that is continuous (Katz and Miledi, 1977; Vyskocil et al., 2009). Such nonvesicular release is undetectable in our recording conditions. The amount of continuous ACh release has been hypothesized to be two orders of magnitude greater than that released during mEPCs (Katz and Miledi, 1977; Vyskocil et al., 2009). Perhaps block of this continuous neurotransmission underlies the induction of the increase in QC. We tested whether increasing continuous ACh signaling could prevent the D-TC effect by adding ACh to the bath. We used $0.1 \mathrm{~mm} \mathrm{ACh}$, a dose that triggers relatively mild desensitization of $\mathrm{nAChRs}$ and thus would be expected to greatly increase continuous ACh-mediated current. To avoid the possibility of activation of muscarinic $\mathrm{nAChRs}$ by the addition of ACh, $10 \mu \mathrm{M}$ atropine was also added. The increase in QC after application of D-TC was unaffected by the addition of ACh to the bath (Fig. $3 H$ ). These data suggest that increasing continuous activation of nAChRs by application of agonist has no effect on the signaling triggered by application of D-TC.

\section{Efficacy of different blocker of nAChRs}

We wished to determine whether all blockers of nicotinic nAChRs had the same efficacy in triggering the increase in QC. It has been reported that vecuronium blocks nAChRs, but does not trigger an increase in QC (Tian et al., 1994). However, when we applied vecuronium, the QC increase was similar to other blockers of nAChRs (Fig. 4A). We measured the efficacy of both competitive and noncompetitive blockers of nAChRs. Both D-TC and gallamine are reversible competitive antagonists (Rang et al., 2003; Ostroumov et al., 2008). Mecamylamine is a noncompetitive antagonist that does not block binding of ACh to the nAChR but instead is an open-channel blocker (Varanda et al., 1985). We compared the efficacies of gallamine and mecamylamine with those of D-TC, vecuronium, and BTX and found that all of these blockers had similar efficacy in increasing QC (Fig. 4B). In contrast, succinylcholine blocked nAChRs, as indicated by the decrease of mEPC amplitude, but has partial agonist activity (Marshall et al., 1990; Baraka, 2007) and did not trigger QC upregulation (Fig. 4C,D).

It is possible that because of the partial agonist activity, $\mathrm{mEPC}$ amplitude was not reduced to the same extent as after application of blockers with no agonist activity and this was why QC was not increased after application of ACh and succinylcholine. To inves- 
A

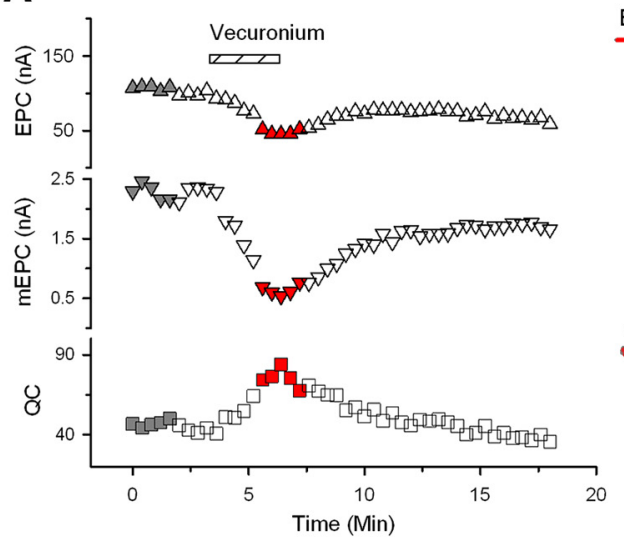

Vecuronium

before
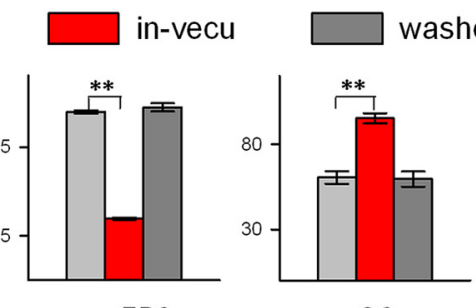

QC

\section{C}

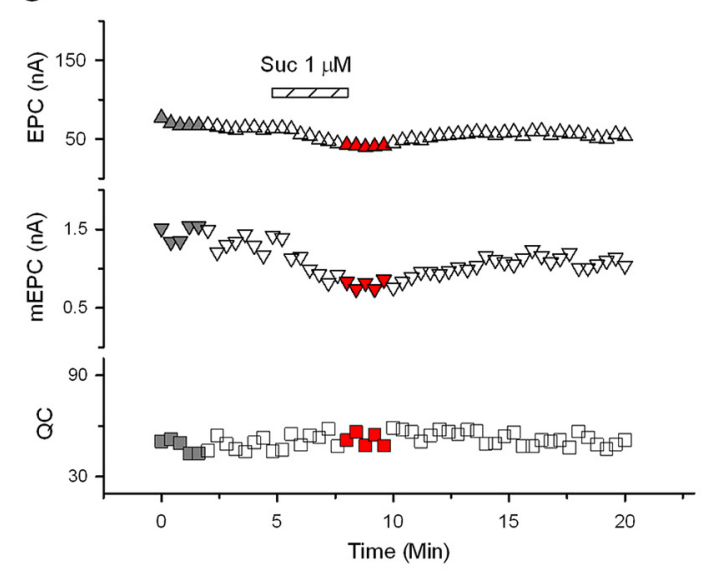

E

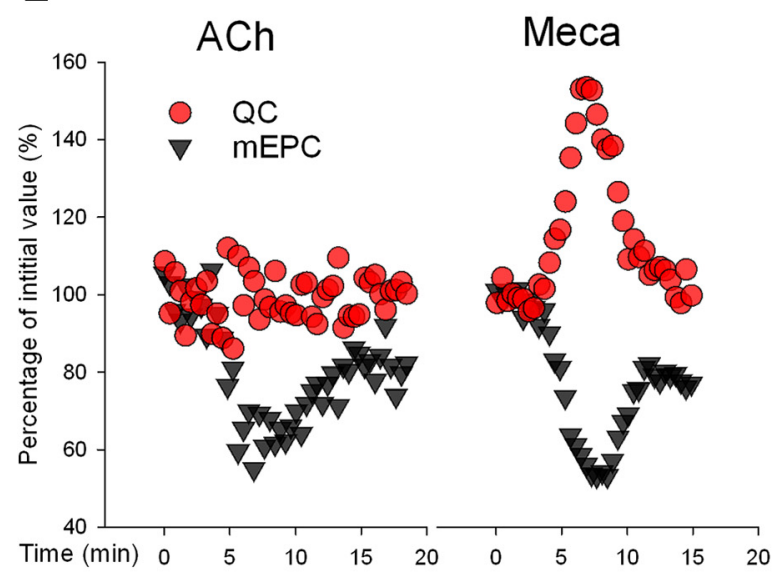

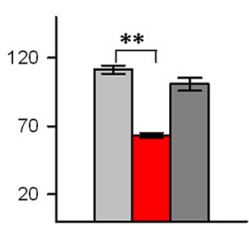

EPC

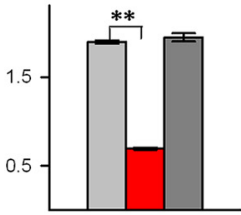

mEPC
B
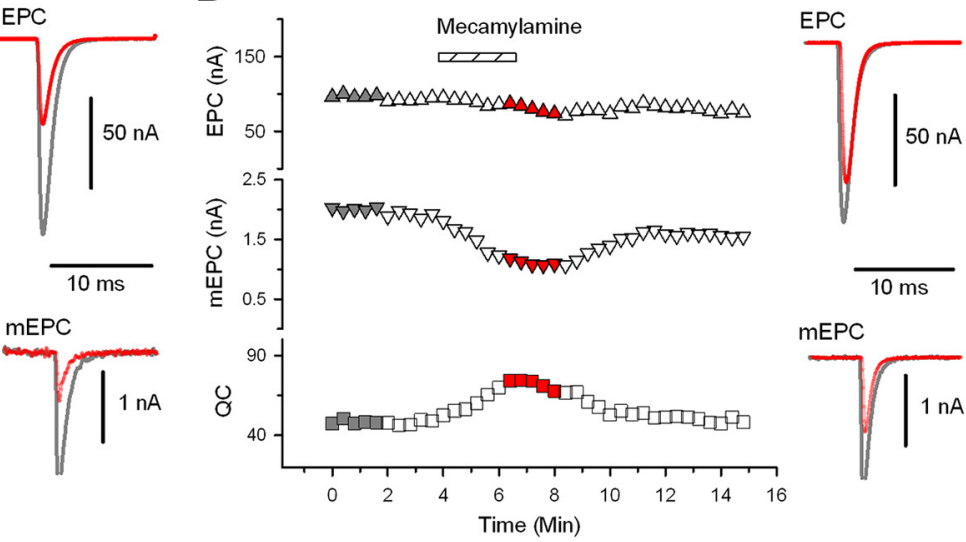

MEPC

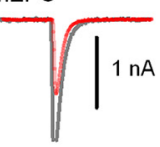

Mecamylamine

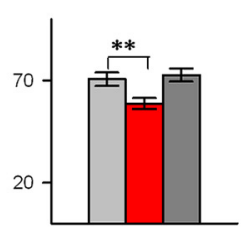

EPC
Before $\square$ Meca

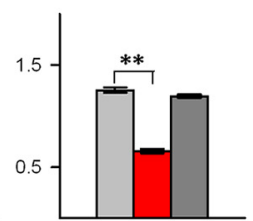

mEPC

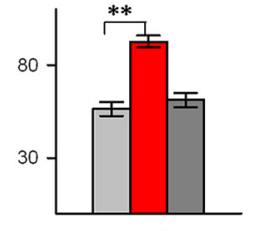

QC

D
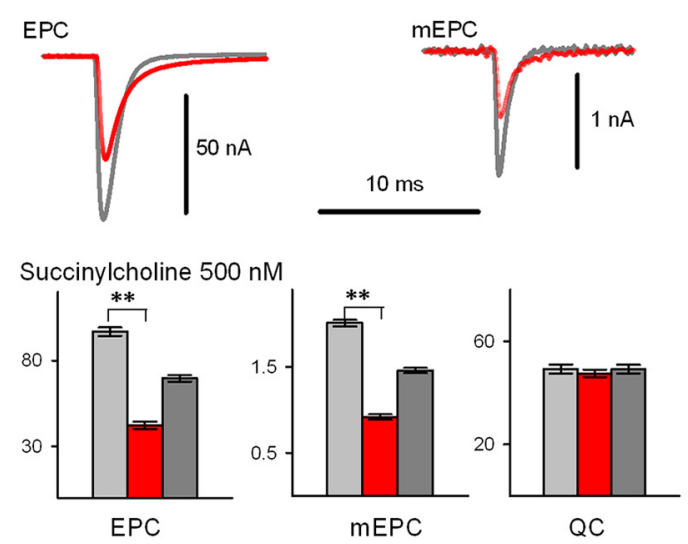

F

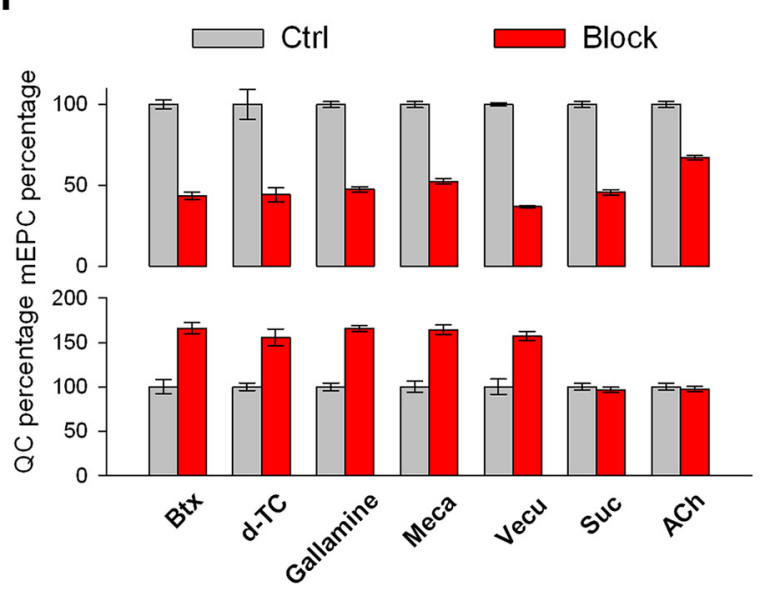

Figure 4. Upregulation of $Q C$ occurs only in blockers with no agonist activity. $A$, Application of vecuronium triggers upregulation of $\mathrm{QC}$. Left, Plot of average EPC and $\mathrm{mEPC}$ amplitude and $\mathrm{QC}$ before and after infusion of vecuronium $(0.25 \mu \mathrm{M})$ at the time indicated. Right, Averaged EPC and $\mathrm{mEPC}$ traces before (gray) and in the presence of vecuronium (red) taken from times corresponding to colored symbols on the plot on the left. Below are plots of mean EPC, mEPC, QC, and mEPC amplitude before ( $n=10$ muscle, $35 \mathrm{NMJs})$, during ( $n=10$ muscles, 99 NMJs) and after washout of vecuronium ( $n=10$ muscles, 45 NMJs. For these experiments, muscle was held at $-70 \mathrm{mV}$ and contraction was prevented by addition of $2 \mu \mathrm{m}$ (Figure legend continues.) 
tigate this, we compared the magnitude of reduction of mEPC amplitude with the percentage increase in QC for all blockers tested and found that the reduction in $\mathrm{MEPC}$ amplitude was similar after drugs that did and did not trigger increased QC (Fig. $4 E, F)$. Therefore, the lack of increase in QC could not be explained by a less severe block of synaptic transmission.

\section{Increase in QC is associated with a speeding of mEPC decay}

If block of nAChRs does not trigger increased QC by reducing synaptic current, what possible explanations remain? We considered the possibility that nAChRs undergo a conformational change after application of blocker. Evidence consistent with a conformational change in nAChRs came from analysis of the rate of decay of mEPCs. After partial block of nAChRs with blockers with no agonist activity, there was a small, but statistically significant increase in the rate of decay of mEPCs (Fig. 5). At CNS synapses, the presence of multiple receptor types made up of different mixes of subunits means that changes in the kinetics of currents could be due to preferential block of certain receptor subtypes. This is not the case at the mouse NMJ, where there is only one type of nAChR at the adult NMJ that is made up of an identical mix of subunits (Unwin, 2013; Auerbach, 2015). Therefore, the more rapid $\mathrm{mEPC}$ decay could indicate a change in behavior of the adult $\alpha 1$-containing muscle AChR.

It is known that the time constant of MEPC and EPC decay and the mean open time of ACh-gated channels is voltage dependent (Magleby and Stevens, 1972); however, we voltage clamped individual NMJs at the same potential before and after toxin application and therefore voltage-dependent differences in nAChRs open time does not explain the differences in mEPC decay. Another possible explanation for the increase in rate of $\mathrm{mEPC}$ decay is that blockers decrease the density of ACh-binding sites and thereby accelerate the diffusion of ACh from the synaptic cleft, which is manifested by more rapid decay of the synaptic current (Katz and Miledi, 1973).

If a conformational change in nAChRs is involved in signaling the increase in QC, then blockers that trigger the increase in QC should trigger an increase in rate of decay even if they have different mechanisms of action. Consistent with this possibility, blockers that triggered increased QC had significant shortening of mEPC decay time (Fig. 5B). In the case of mecamylamine, single-channel recordings have shown that the increase rate of decay is likely secondary to a shorter channel open time (Varanda

\section{$\leftarrow$}

(Figure legend continued.) $\mu$-Ctx (Table 1). B, Application of mecamylamine triggers upregulation of QC. The same experimental protocol was used as described in $A$ for vecuronium. Mecamylamine $(12 \mu \mathrm{M})$ triggered similar changes in EPC and mEPC amplitude and a similar increase in QC. Bottom summarizes data from 6 muscles before mecamylamine $(n=31 \mathrm{NMJs})$ and during ( $n=32$ NMJs) and after washout ( $n=43 \mathrm{NMJs}$ ) (Table 1). C, Application of succinylcholine fails to trigger upregulation of $Q C$. Left, Plot of average EPC and $\mathrm{mEPC}$ amplitude and $\mathrm{QC}$ before and after infusion of succinylcholine $(1 \mu \mathrm{M})$ at the time indicated. $D$, Averaged EPC and $\mathrm{mEPC}$ traces before (gray) and in the presence of succinylcholine (red), taken from times corresponding to colored symbols on the plot shown in C. Bottom, mean data from 10 muscles treated with succinylcholine ( $500 \mathrm{~nm}): n=61$ NMJs before, $n=87 \mathrm{NMJs}$ during succinylcholine infusion, and 76 NMJs after washout (Table 1). $\boldsymbol{E}$, Comparison of changes in $\mathrm{mEPC}$ amplitude (gray triangle) and QC (red circle) induced by infusion of ACh (left) or by infusion of mecamylamine (right). All the values shown were normalized to the average value (as 100\%) from the beginning of the plots, respectively. Although mEPC amplitude was reduced by a similar proportion, QC increased during mecamylamine infusion, but not ACh infusion. $\boldsymbol{F}$, Summary of changes in mEPC amplitude and QC induced by BTX (control, 51 NMJs and BTX, 78 NMJs), D-TC (29 and 25), gallamine (33 and 55), mecamylamine (Meca, 31 and 43), vecuronium (33 and 99), succinylcholine (suc, 61 and 87), and ACh (43 and 102). ${ }^{* *} p<.01$. Averaged values were scaled to controls, which were set at $100 \%$. et al., 1985). Succinylcholine, the only nAChR blocker that did not trigger an increase in QC, triggered prolongation in mEPC decay rather than a shortening. This increase in decay time has been shown to be due to a longer open time of ACh-activated currents (Nojima et al., 1992). Desensitization of nAChRs with ACh or CCh triggered a slight, but statistically significant, speeding of mEPC decay. The increase in decay rate after desensitization was statistically significantly less than the increase in decay rate induced by blockers that triggered the increase in QC (Fig. 5). Because desensitization of nAChRs with ACh or CCh decreases the number of unoccupied ACh-binding sites, there should have been a similar increase in diffusion of ACh such that mEPC decay should have been similarly shortened. The finding that mEPC shortening was less after desensitization is consistent with the possibility that part of the shortening is due to a conformational change in unblocked nAChRs.

\section{Discussion}

It has been proposed that disruption of synaptic transmission is sensed to trigger homeostatic upregulation of QC at the NMJ (Rich and Wenner, 2007; Frank, 2014; Davis and Müller, 2015). Studies performed to determine how disruption of synaptic transmission is sensed led us to propose that interruption of synaptic transmission may not be what is sensed to trigger synaptic plasticity at the mouse NMJ. We instead suggest that muscle $\alpha 1$ containing nicotinic nAChRs may serve as signaling molecules that trigger synaptic plasticity at the NMJ.

\section{Technical considerations}

Given the surprising nature of our hypothesis that block of postsynaptic AChRs triggers directly an increase in presynaptic release of ACh within seconds, it is worth considering the possibility that our findings are due to an artifact of the way that we performed the experiments. For example, the change in QC could be due to different $\mathrm{ACh}$ concentrations during the EPC and mEPC; because of the much higher concentration of ACh in the synaptic cleft during the EPC than in $\mathrm{MEPC}$, antagonist blockade could more efficiently decrease the mEPC compared with the $\mathrm{EPC}$, thus altering the EPC/mEPC ratio. This issue would be compounded if there was focal multivesicular release, as has been demonstrated at CNS synapses (Wadiche and Jahr, 2001; Taschenberger et al., 2002). Alternatively, there could be an issue with voltage clamp of the larger EPC and better clamp is achieved after partial block of nAChRs. Both of these possibilities would lead to the incorrect conclusion that QC was increased after partial block of nAChRs. Supporting both of these possibilities is the finding that, when QC is lowered by decreasing external $\mathrm{Ca}^{2+}$, the increase in QC is no longer seen (Tian et al., 1994; Wang et al., 2016).

What then, is our evidence that the increase in QC is real? One finding suggesting the increase is real is that block with BTX triggers the same increase as D-TC. BTX binds nAChRs with high affinity (Lukas et al., 1981) such that a higher concentration of $\mathrm{ACh}$ in the cleft during evoked release will not overcome block. Furthermore, the increase can be prevented by two manipulations that have minimal effect on EPC and mEPC amplitude. The first manipulation is block of vesicle refilling with vesamicol. Although this eventually leads to reduction of EPC amplitude, before causing a significant reduction in EPC amplitude it eliminates the increase in QC after infusion of D-TC (Wang et al., 2016). Second, mice that have $\mathrm{Ca}^{2+}$ indicator dye expressed presynaptically (perhaps buffering presynaptic $\mathrm{Ca}^{2+}$ ) have normal EPC amplitude, but a significantly blunted increase in QC after 

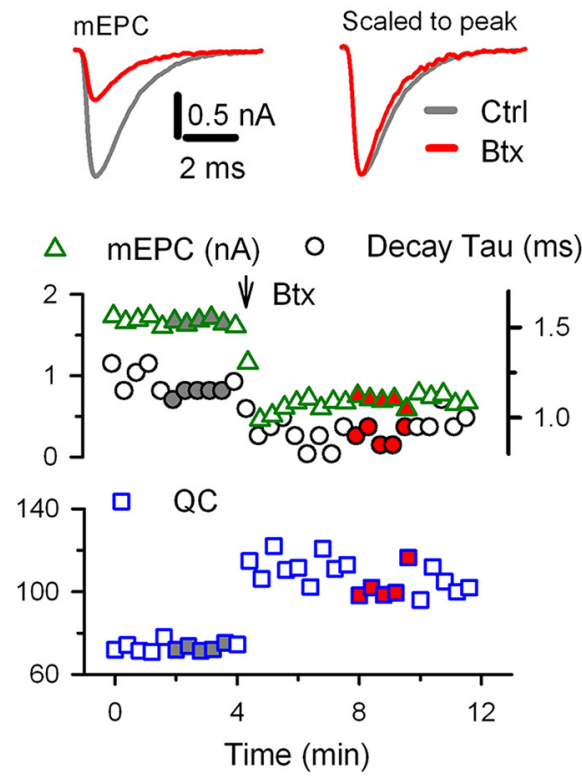

C

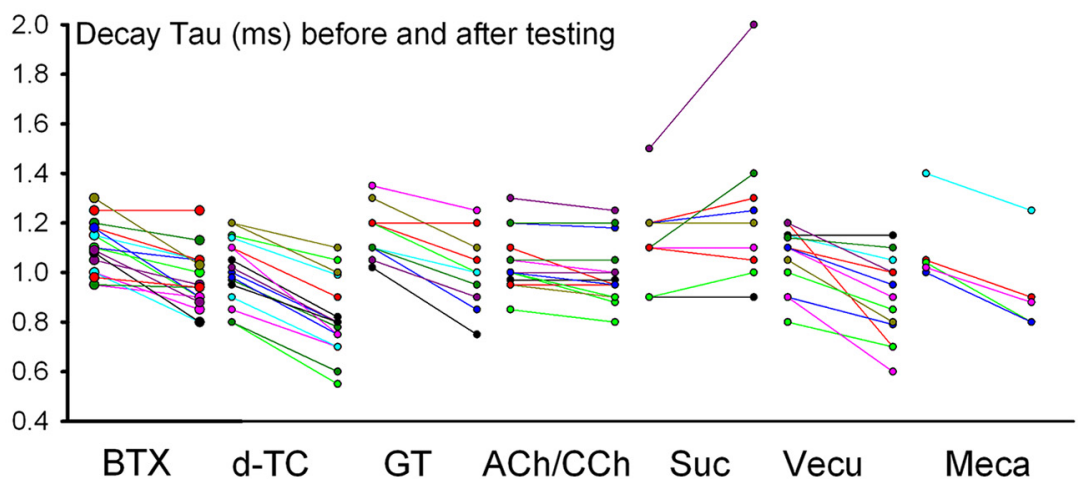

Figure 5. Upregulation of $\mathrm{QC}$ correlates with an increase in decay rate of $\mathrm{mEPC} . A$, Plots of averaged $\mathrm{mEPC}$ amplitude (triangle), decay tau* (circle), and QC (square) against time. Data were acquired using a protocol shown in Figure $1 A$. BTX ( $200 \mu \mathrm{g} / \mathrm{ml})$ was pressure puffed onto the endplate at the time indicated by the arrow. Left top, Superimposed mEPC traces (left) and peak normalized traces (right) shown were averaged from the time points indicated by the gray and red filled symbols on the $\mathrm{mEPC}$ plot (middle). For reference, same colorations apply to symbols in QC plot (bottom). $\boldsymbol{B}$, Decay constant of $\mathrm{mEPC}$ in the presence of drug relative to that of control. The same endplate was used to obtain $\mathrm{mEPC}$ values in the presence and absence of drug and the number of endplates in each case is indicated in parentheses. Statistically significant decrease in normalized decay time constant was seen in all pairs (except for an increase in succinylcholine) (Table 1). Comparison of $\mathrm{mEPC}$ decay time constant reduction between the $\mathrm{ACh} / \mathrm{CCh}$ group and the BTX group yielded significance $\left(t_{(38)}=4.197, p=1.57 \mathrm{E}-4, t\right.$ test). GT, Gallamine. C, Scattered plots of $\mathrm{mEPC}$ decay tau before and in the presence of $\mathrm{nAChR}$ antagonists. Two measurements of each endplate are connected by a colored line. Data are from the same experiments shown in $\boldsymbol{B}$ (Table 1). ${ }^{*}$ The rate of decay was measured as the time elapsed from the peak of the averaged $\mathrm{mEPC}$ to peak/e.

infusion of D-TC (Wang et al., 2016). Finally, mEPC and EPC amplitudes were reduced after application of ACh and succinylcholine without triggering an increase in QC. The finding that synaptic current can be reduced without triggering an increase in QC rules out technical artifacts such as poor voltage clamp of large currents. Our interpretation is that the increase in QC is real and is due to mobilization of a unique pool of synaptic vesicles in a manner that is dependent on elevation of presynaptic $\mathrm{Ca}^{2+}$ (Wang et al., 2016).

\section{Triggers of homeostatic synaptic plasticity at different synapses}

It has been proposed that spiking activity is sensed by CNS neurons to trigger homeostatic upregulation of quantal amplitude (synaptic scaling) (Turrigiano et al., 1998; Burrone et al., 2002; Stellwagen and Malenka, 2006). If this is the case, then it would suggest that the way in which disruption of synaptic activity is sensed at central synapses is fundamentally different from the way that disruption is sensed at the NMJ. However, it was recently demonstrated that restoring network activity to baseline levels in the presence of ongoing block of neurotransmission had no effect on synaptic scaling (Fong et al., 2015; Garcia-Bereguiain et al., 2016). These findings strongly suggest blocking neurotransmitter receptors is sufficient to trigger homeostatic plasticity independent of network activity in the CNS and raise the possibility that the signals triggering homeostatic regulation are similar at CNS synapses and the NMJ.

At CNS synapses, homeostatic synaptic plasticity can also be triggered by blocking $\mathrm{Na}$ channels rather than neurotransmitter receptors (Turrigiano et al., 1998; Burrone et al., 2002; Stellwagen and Malenka, 2006). Do similar forms of homeostatic plasticity exist at the NMJ? At the mouse NMJ, block of evoked activity triggers an increase in probability of vesicle release and an increase in quantal amplitude that is independent of $\mathrm{nAChR}$ block (Wang et al., 2004, 2005, 2010) and, at the Drosophila NMJ, postsynaptic overexpression of $\mathrm{K}$ channels triggers an increase in QC despite normal activation of glutamate receptors (Paradis et al., 2001). These forms of synaptic plasticity appear to be triggered by disruption of activation of the presynaptic nerve terminal or the postsynaptic muscle fiber rather than block of neurotransmitter receptors and thus represent homeostatic synaptic plasticity that is triggered by disruption of synaptic transmission. This suggests that at both the NMJ and central synapses there are at least two different sensors that can independently trigger homeostatic synaptic plasticity. Some sensors monitor synaptic/network activity, whereas others may sense factors that are independent of synaptic/network activity. At the NMJ, each sensor engages different mechanisms to homeostatically regulate synaptic strength (Wang et al., 2010).

\section{Differences between homeostatic regulation at the mouse and Drosophila NMJ}

The system in which the molecular mechanisms underlying homeostatic upregulation of QC has been studied in the greatest detail is the Drosophila NMJ. Most relevant to the current study, two different retrograde signaling molecules have been identified (Wang et al., 2014; Orr et al., 2017). The retrograde molecular signals act to modify presynaptic actin to potentiate the readily releasable pool, increase insertion of $\mathrm{DegENaC}$ channels into the presynaptic membrane, and increase $\mathrm{Ca}^{2+}$ entry through presyn- 
aptic $\mathrm{Ca}_{\mathrm{v} 2.1}$ channels (Müller and Davis, 2012; Younger et al., 2013; Orr et al., 2017). All of these changes appear to contribute to the increase in QC.

Could the same molecular signals underlie the retrograde homeostatic signaling occurring at the mouse NMJ? In both systems, block of postsynaptic neurotransmitter receptors triggers an upregulation in presynaptic QC that occurs relatively rapidly. Although the similarities suggest that the answer certainly could be yes, there are two differences that suggest caution should be used when extrapolating results from Drosophila to the mammalian NMJ. First, in the mouse, upregulation of QC occurs as rapidly as it can be measured (Wang et al., 2016). In Drosophila, there is a several minute lag between block of receptors and upregulation of QC (Frank et al., 2006). Second, reduction of external $\mathrm{Ca}^{2+}$ concentration eliminates the upregulation of $\mathrm{QC}$ at the mouse NMJ (Tian et al., 1994; Wilson et al., 1995; Wang et al., 2016). In Drosophila, the increase in QC occurs at all levels of extracellular $\mathrm{Ca}^{2+}$ (Frank et al., 2006; Müller et al., 2015; Orr et al., 2017). These dissimilarities suggest fundamental differences in homeostatic mechanisms between the mouse and Drosophila NMJ.

\section{Type and location of $n A C h R s$ for which block triggers the increase in QC}

Two assumptions underlying our interpretation of the data are that the nAChRs blocked are located on the postsynaptic muscle fiber and that there is only a single type of nAChR present on the muscle fiber. The data for and against our assumptions are considered below.

It has been hypothesized that block of $\alpha 7$-containing nicotinic nAChRs present on the presynaptic nerve terminal at the $\mathrm{NMJ}$ is responsible for the rapid upregulation of QC after block of nAChRs (Bowman et al., 1990; MacDermott et al., 1999). We ruled out involvement of presynaptic $\alpha 7 \mathrm{nAChRs}$ as the trigger using $\alpha 7$ knock-out mice and toxins selective for the $\alpha 1$ versus $\alpha 7$ AChR subunits (Luo and McIntosh, 2004; Whiteaker et al., 2007). Our data strongly suggest that block of $\alpha 1$-containing $\mathrm{nAChRs} \mathrm{triggers} \mathrm{the} \mathrm{upregulation} \mathrm{of} \mathrm{QC.} \mathrm{Because} \mathrm{we} \mathrm{are} \mathrm{aware} \mathrm{of}$ no evidence that either Schwann cells or the presynaptic motor terminal express $\alpha$-1-containing nAChRs, we favor the possibility that block of $\alpha$-1-containing nAChRs on the postsynaptic muscle fiber triggers the upregulation of QC.

A second possibility that would complicate interpretation is that there might be two different types of nAChRs at the NMJ with differential sensitivity to block. If spontaneous and evoked release differentially activated the two nAChR subtypes, then this could lead to erroneous conclusions about changes in QC after block. For example, if the nAChRs preferentially activated by spontaneous release were more sensitive to block, one could erroneously conclude that QC is increased after block. Support for this possibility comes from studies at a number of different synapses, which suggest the vesicle pools responsible for evoked and spontaneous release are distinct (for review, see Kavalali, 2015). However, there is no evidence for multiple nAChR subtypes at the adult, innervated NMJ (Unwin, 2013; Auerbach, 2015). Nevertheless, it remains possible that two populations exist and this could account for our findings. The following data argue against this possibility: when extracellular $\mathrm{Ca}^{2+}$ is lowered, partial block of nAChRs triggers no increase in QC (Tian et al., 1994; Wang et al., 2016). Similarly, there is no nAChR block-induced upregulation of $\mathrm{QC}$ when vesamicol is added to prevent refilling of vesicles (Wang et al., 2016). If there were two types of nAChRs differentially activated by spontaneous and evoked release and the
nAChR types had differential sensitivity to blockers, then one would not expect there to be situations in which block of nAChRs would not cause the apparent upregulation of QC.

\section{How block of nAChRs is sensed}

The nAChR-block-induced increase in QC did not require prior evoked release and could be triggered in NMJs of fibers that were voltage clamped. These data indicate that neither evoked release nor membrane potential is sensed to trigger the increase in QC. Another possibility is that $\mathrm{Ca}^{2+} /$ ion flow through nAChRs during spontaneous release of $\mathrm{ACh}$ is sensed (Bregestovski et al., 1979; Vernino et al., 1994). Block of $\mathrm{Ca}^{2+}$ flow through postsynaptic receptors has been proposed as the sensor for homeostatic plasticity at the frog, mouse, and Drosophila NMJ (Frank et al., 2006; Ouanounou et al., 2016). We addressed this possibility by applying agonist and found no relationship between reduction of current flow through nAChRs and upregulation of QC. These data raise the possibility that reduction of neither $\mathrm{Ca}^{2+}$ entry nor synaptic current is the signal sensed. Further experiments directly measuring $\mathrm{Ca}^{2+}$ entry would be required to confirm this conjecture.

One way that nAChRs could initiate signaling is by undergoing a conformational change. Evidence consistent with unblocked nAChRs undergoing a conformational change comes from the finding that block of nAChRs triggers a small, but statistically significant increase in the rate of decay of mEPCs. The increase in rate of decay cannot be explained by an effect of membrane potential on decay rate (Magleby and Stevens, 1972) or competition between ligand and blocker (Wadiche and Jahr, 2001) because it occurs after block with an essentially irreversible blocker (BTX). It is possible that the increase in decay rate is due to occupation of ACh-binding sites, which leads to an increase in the rate of diffusion of ACh out of the synaptic cleft (Katz and Miledi, 1973). However, desensitization of nAChRs with ACh or $\mathrm{CCh}$ also causes a decrease in ACh-binding sites available, but does not trigger as big an increase in decay rate. Reduction of mEPC amplitude by application of ACh and succinylcholine, two treatments that did not trigger the same increase in decay rate, did not trigger an increase in QC. These data raise the possibility that there is a conformational change in unblocked nAChRs that may be responsible for the increase in $\mathrm{MEPC}$ decay.

The signaling role that we are proposing for $\mathrm{nAChRs}$ at the NMJ has been termed noncanonical signaling (Valbuena and Lerma, 2016). In noncanonical signaling, ionotropic neurotransmitter receptors also serve as signaling molecules. Noncanoncial signaling involving nAChRs has been shown previously in leukocytes (Razani-Boroujerdi et al., 2007; Hecker et al., 2015; Richter et al., 2016). Ours is the first study to suggest that postsynaptic nAChRs may be involved in noncanonical signaling that regulates synaptic function and that noncanonical signaling may be involved in triggering homeostatic synaptic plasticity. Because nAChRs have been implicated in a number of disease states involving the nervous system (Del Bufalo et al., 2014; Deutsch et al., 2015; Lombardo and Maskos, 2015), the hypothesis that nAChRs may trigger synaptic plasticity directly has wide-reaching implications.

\section{References}

Adams DJ, Dwyer TM, Hille B (1980) The permeability of endplate channels to monovalent and divalent metal cations. J Gen Physiol 75:493-510. CrossRef Medline

Albuquerque EX, Pereira EF, Alkondon M, Rogers SW (2009) Mammalian nicotinic acetylcholine receptors: from structure to function. Physiol Rev 89:73-120. CrossRef Medline 
Auerbach A (2015) Activation of endplate nicotinic acetylcholine receptors by agonists. Biochem Pharmacol 97:601-608. CrossRef Medline

Baraka A. depolarizing block is an endplate-muscular block, not a neuromuscular block. Anesthesiology 106:399-400, 2007; author reply 400.

Bowman WC, Prior C, Marshall IG (1990) Presynaptic receptors in the neuromuscular junction. Ann N Y Acad Sci 604:69-81. CrossRef Medline

Bregestovski PD, Miledi R, Parker I (1979) Calcium conductance of acetylcholine-induced endplate channels. Nature 279:638-639. CrossRef Medline

Burrone J, O’Byrne M, Murthy VN (2002) Multiple forms of synaptic plasticity triggered by selective suppression of activity in individual neurons. Nature 420:414-418. CrossRef Medline

Cull-Candy SG, Miledi R, Trautmann A, Uchitel OD (1980) On the release of transmitter at normal, myasthenia gravis and myasthenic syndrome affected human end-plates. J Physiol 299:621-638. CrossRef Medline

Davis GW, Müller M (2015) Homeostatic control of presynaptic neurotransmitter release. Annu Rev Physiol 77:251-270. CrossRef Medline

Del Bufalo A, Cesario A, Salinaro G, Fini M, Russo P (2014) Alpha9 alpha10 nicotinic acetylcholine receptors as target for the treatment of chronic pain. Curr Pharm Des 20:6042-6047. CrossRef Medline

Deutsch SI, Burket JA, Urbano MR, Benson AD (2015) The alpha7 nicotinic acetylcholine receptor: a mediator of pathogenesis and therapeutic target in autism spectrum disorders and down syndrome. Biochem Pharmacol 97:363-377. CrossRef Medline

Fong MF, Newman JP, Potter SM, Wenner P (2015) Upward synaptic scaling is dependent on neurotransmission rather than spiking. Nat Commun 6:6339. CrossRef Medline

Frank CA (2014) Homeostatic plasticity at the Drosophila neuromuscular junction. Neuropharmacology 78:63-74. CrossRef Medline

Frank CA, Kennedy MJ, Goold CP, Marek KW, Davis GW (2006) Mechanisms underlying the rapid induction and sustained expression of synaptic homeostasis. Neuron 52:663-677. CrossRef Medline

Garcia-Bereguiain MA, Gonzalez-Islas C, Lindsly C, Wenner P (2016) Spontaneous release regulates synaptic scaling in the embryonic spinal network in vivo. J Neurosci 36:7268-7282. CrossRef Medline

Harborne AJ, Bowman WC, Marshall IG (1988) Effects of tubocurarine on end-plate current rundown and quantal content during rapid nerve stimulation in the snake. Clin Exp Pharmacol Physiol 15:479-490. CrossRef Medline

Hecker A, Küllmar M, Wilker S, Richter K, Zakrzewicz A, Atanasova S, Mathes V, Timm T, Lerner S, Klein J, Kaufmann A, Bauer S, Padberg W, Kummer W, Janciauskiene S, Fronius M, Schweda EK, Lochnit G, Grau V (2015) Phosphocholine-modified macromolecules and canonical nicotinic agonists inhibit ATP-induced IL-1beta release. J Immunol 195: 2325-2334. CrossRef Medline

Innocent $\mathrm{N}$, Livingstone $\mathrm{PD}$, Hone A, Kimura A, Young $\mathrm{T}$, Whiteaker P, McIntosh JM, Wonnacott S (2008) Alpha-conotoxin arenatus IB [V11L, V16D] [corrected] is a potent and selective antagonist at rat and human native alpha7 nicotinic acetylcholine receptors J Pharmacol Exp Ther 327:529-537. CrossRef Medline

Johnson DS, Martinez J, Elgoyhen AB, Heinemann SF, McIntosh JM (1995) alpha-conotoxin ImI exhibits subtype-specific nicotinic acetylcholine receptor blockade: preferential inhibition of homomeric alpha 7 and alpha 9 receptors. Mol Pharmacol 48:194-199. Medline

Katz B, Miledi R (1973) The binding of acetylcholine to receptors and its removal from the synaptic cleft. J Physiol 231:549-574. CrossRef Medline

Katz B, Miledi R (1977) Transmitter leakage from motor nerve endings. Proc R Soc Lond B Biol Sci 196:59-72. CrossRef Medline

Katz B, Miledi R (1978) A re-examination of curare action at the motor endplate. Proc R Soc Lond B Biol Sci 203:119-133. CrossRef Medline

Kavalali ET (2015) The mechanisms and functions of spontaneous neurotransmitter release. Nat Rev Neurosci 16:5-16. CrossRef Medline

Kushmerick C, Renden R, von Gersdorff H (2006) Physiological temperatures reduce the rate of vesicle pool depletion and short-term depression via an acceleration of vesicle recruitment. J Neurosci 26:1366-1377. CrossRef Medline

Lombardo S, Maskos U (2015) Role of the nicotinic acetylcholine receptor in Alzheimer's disease pathology and treatment. Neuropharmacology 96 : 255-262. CrossRef Medline

Lukas RJ, Morimoto H, Hanley MR, Bennett EL (1981) Radiolabeled alphabungarotoxin derivatives: kinetic interaction with nicotinic acetylcholine receptors. Biochemistry 20:7373-7378. CrossRef Medline
Luo S, McIntosh JM (2004) Iodo-alpha-conotoxin MI selectively binds the alpha/delta subunit interface of muscle nicotinic acetylcholine receptors. Biochemistry 43:6656-6662. CrossRef Medline

MacDermott AB, Role LW, Siegelbaum SA (1999) Presynaptic ionotropic receptors and the control of transmitter release. Annu Rev Neurosci 22: 443-485. CrossRef Medline

Magleby KL, Stevens CF (1972) The effect of voltage on the time course of end-plate currents. J Physiol 223:151-171. CrossRef Medline

Marshall CG, Ogden DC, Colquhoun D (1990) The actions of suxamethonium (succinyldicholine) as an agonist and channel blocker at the nicotinic receptor of frog muscle. J Physiol 428:155-174. CrossRef Medline

Miledi R, Molenaar PC, Polak RL (1978) Alpha-bungarotoxin enhances transmitter "released" at the neuromuscular junction. Nature 272:641643. CrossRef Medline

Molenaar PC, Polak RL, Miledi R, Alema S, Vincent A, Newsom-Davis J (1979) Acetylcholine in intercostal muscle from myasthenia gravis patients and in rat diaphragm after blockade of acetylcholine receptors. Prog Brain Res 49:449-458. CrossRef Medline

Molenaar PC, Oen BS, Plomp JJ, Van Kempen GT, Jennekens FG, Hesselmans LF (1991) A non-immunogenic myasthenia gravis model and its application in a study of transsynaptic regulation at the neuromuscular junction. Eur J Pharmacol 196:93-101. CrossRef Medline

Müller M, Davis GW (2012) Transsynaptic control of presynaptic Ca(2)(+) influx achieves homeostatic potentiation of neurotransmitter release. Curr Biol 22:1102-1108. CrossRef Medline

Müller M, Genç Ö, Davis GW (2015) RIM-binding protein links synaptic homeostasis to the stabilization and replenishment of high release probability vesicles. Neuron 85:1056-1069. CrossRef Medline

Nojima H, Muroi M, Kimura I, Kimura M (1992) Indirect inhibitory effect of succinylcholine on acetylcholine-activated channel activities and its modulation by external Ca2 + in mouse skeletal muscles. Br J Pharmacol 105:23-26. CrossRef Medline

Orr BO, Fetter RD, Davis GW (2017) Retrograde semaphorin-plexin signalling drives homeostatic synaptic plasticity. Nature 550:109-113. CrossRef Medline

Ostroumov K, Shaikhutdinova A, Skorinkin A (2008) Modeling study of mecamylamine block of muscle type acetylcholine receptors. Eur Biophys J 37:393-402. CrossRef Medline

Ouanounou G, Baux G, Bal T (2016) A novel synaptic plasticity rule explains homeostasis of neuromuscular transmission. eLife 5 .

Paradis S, Sweeney ST, Davis GW (2001) Homeostatic control of presynaptic release is triggered by postsynaptic membrane depolarization. Neuron 30:737-749. CrossRef Medline

Plomp JJ, van Kempen GT, Molenaar PC (1992) Adaptation of quantal content to decreased postsynaptic sensitivity at single endplates in alphabungarotoxin-treated rats. J Physiol 458:487-499. CrossRef Medline

Plomp JJ, van Kempen GT, Molenaar PC (1994) The upregulation of acetylcholine release at endplates of alpha-bungarotoxin-treated rats: its dependency on calcium. J Physiol 478:125-136. CrossRef Medline

Plomp JJ, Van Kempen GT, De Baets MB, Graus YM, Kuks JB, Molenaar PC (1995) Acetylcholine release in myasthenia gravis: regulation at single end-plate level. Ann Neurol 37:627-636. CrossRef Medline

Rang HP, Dale MM, Ritter JM, Moore PK (2003) Pharmacology, Ed 5. New York: Churchill Livingstone.

Razani-Boroujerdi S, Boyd RT, Dávila-García MI, Nandi JS, Mishra NC, Singh SP, Pena-Philippides JC, Langley R, Sopori ML (2007) T cells express alpha7-nicotinic acetylcholine receptor subunits that require a functional TCR and leukocyte-specific protein tyrosine kinase for nicotine-induced Ca2+ response. J Immunol 179:2889-2898. CrossRef Medline

Rich MM, Wenner P (2007) Sensing and expressing homeostatic synaptic plasticity. Trends Neurosci 30:119-125. CrossRef Medline

Richter K, Mathes V, Fronius M, Althaus M, Hecker A, Krasteva-Christ G, Padberg W, Hone AJ, McIntosh JM, Zakrzewicz A, Grau V (2016) Phosphocholine: an agonist of metabotropic but not of ionotropic functions of alpha9-containing nicotinic acetylcholine receptors. Sci Rep 6:28660. CrossRef Medline

Rochon D, Rousse I, Robitaille R (2001) Synapse-glia interactions at the mammalian neuromuscular junction. J Neurosci 21:3819-3829. Medline

Stellwagen D, Malenka RC (2006) Synaptic scaling mediated by glial TNFalpha. Nature 440:1054-1059. CrossRef Medline

Taschenberger H, Leão RM, Rowland KC, Spirou GA, von Gersdorff H 
(2002) Optimizing synaptic architecture and efficiency for highfrequency transmission. Neuron 36:1127-1143. CrossRef Medline

Tian L, Prior C, Dempster J, Marshall IG (1994) Nicotinic antagonistproduced frequency-dependent changes in acetylcholine release from rat motor nerve terminals. J Physiol 476:517-529. CrossRef Medline

Turrigiano G (2012) Homeostatic synaptic plasticity: local and global mechanisms for stabilizing neuronal function. Cold Spring Harb Perspect Biol 4:a005736. CrossRef Medline

Turrigiano GG, Leslie KR, Desai NS, Rutherford LC, Nelson SB (1998) Activity-dependent scaling of quantal amplitude in neocortical neurons. Nature 391:892-896. CrossRef Medline

Unwin N (2013) Nicotinic acetylcholine receptor and the structural basis of neuromuscular transmission: insights from torpedo postsynaptic membranes. Q Rev Biophys 46:283-322. CrossRef Medline

Valbuena S, Lerma J (2016) Non-canonical signaling, the hidden life of ligand-gated ion channels. Neuron 92:316-329. CrossRef Medline

Varanda WA, Aracava Y, Sherby SM, VanMeter WG, Eldefrawi ME, Albuquerque EX (1985) The acetylcholine receptor of the neuromuscular junction recognizes mecamylamine as a noncompetitive antagonist. Mol Pharmacol 28:128-137. Medline

Vernino S, Rogers M, Radcliffe KA, Dani JA (1994) Quantitative measurement of calcium flux through muscle and neuronal nicotinic acetylcholine receptors. J Neurosci 14:5514-5524. Medline

Vyskocil F, Malomouzh AI, Nikolsky EE (2009) Non-quantal acetylcholine release at the neuromuscular junction. Physiol Res 58:763-784. Medline

Wadiche JI, Jahr CE (2001) Multivesicular release at climbing fiberpurkinje cell synapses. Neuron 32:301-313. CrossRef Medline

Wang T, Hauswirth AG, Tong A, Dickman DK, Davis GW (2014) Endosta- tin is a trans-synaptic signal for homeostatic synaptic plasticity. Neuron 83:616-629. CrossRef Medline

Wang X, Engisch KL, Li Y, Pinter MJ, Cope TC, Rich MM (2004) Decreased synaptic activity shifts the calcium dependence of release at the mammalian neuromuscular junction in vivo. J Neurosci 24:10687-10692. CrossRef Medline

Wang X, Li Y, Engisch KL, Nakanishi ST, Dodson SE, Miller GW, Cope TC, Pinter MJ, Rich MM (2005) Activity-dependent presynaptic regulation of quantal size at the mammalian neuromuscular junction in vivo. J Neurosci 25:343-351. CrossRef Medline

Wang X, Wang Q, Engisch KL, Rich MM (2010) Activity-dependent regulation of the binomial parameters $\mathrm{p}$ and $n$ at the mouse neuromuscular junction in vivo. J Neurophysiol 104:2352-2358. CrossRef Medline

Wang X, Pinter MJ, Rich MM (2016) Reversible recruitment of a homeostatic reserve pool of synaptic vesicles underlies rapid homeostatic plasticity of quantal content. J Neurosci 36:828-836. CrossRef Medline

Whiteaker P, Christensen S, Yoshikami D, Dowell C, Watkins M, Gulyas J, Rivier J, Olivera BM, McIntosh JM (2007) Discovery, synthesis, and structure activity of a highly selective alpha7 nicotinic acetylcholine receptor antagonist. Biochemistry 46:6628-6638. CrossRef Medline

Wilson DF (1982) Influence of presynaptic receptors on neuromuscular transmission in rat. Am J Physiol 242:C366-372. CrossRef Medline

Wilson DF, West AE, Lin Y (1995) Inhibitory action of nicotinic antagonists on transmitter release at the neuromuscular junction of the rat. Neurosci Lett 186:29-32. Medline

Younger MA, Müller M, Tong A, Pym EC, Davis GW (2013) A presynaptic $\mathrm{ENaC}$ channel drives homeostatic plasticity. Neuron 79:1183-1196. CrossRef Medline 